\title{
2029 - o fim dos jornais em papel em Portugal? \\ Um estudo longitudinal sobre os principais indicadores de desempenho no sector da imprensa escrita tradicional portuguesa ${ }^{1}$
}

\section{9 - the end of print newspapers in Portugal? A longitudinal study on the main performance indicators in Portugal's traditional print-newspaper industry}

\author{
Tiago Lima Quintanilha*
}

*CIES-IUL - Centro de Investigação e Estudos de Sociologia (ESPP), ISCTE-IUL, Portugal

Resumo

\begin{abstract}
Os novos produtos no formato digital e as novas técnicas tendem a assumir uma forte influência no sector da imprensa escrita e na sua vertente mais tradicional, o formato em papel, consubstanciando-se em agentes de mudança (Küng, 2013; Storsul, 2013) incremental e inovação radical e disruptiva (Sádaba, 2016a, b, c), ao interferirem nas lógicas convencionais de utilização e consumo de notícias por parte dos utilizadores.

Vários autores (Hjarvard, 2012; Barnhurst, 2010; Brock, 2015; Nossek et al, 2015) abordam os efeitos da mutabilidade tecnológica no sector da imprensa escrita e no seu segmento em papel, apontando de forma genérica para cenários em que as vendas de jornais no formato físico têm vindo a diminuir ao longo dos anos, na Era da híper-informação e do imediatismo online, e em função da forte migração dos públicos de notícias para os formatos online sustentados no multiformato, policentralidade e participação (Queuniet, 2011).

A partir da análise longitudinal dos resultados coligidos pela APCT (Associação Portuguesa Para O Controlo De Tiragem E Circulação) sobre o exercício de vendas em papel e tiragens dos principais títulos de imprensa escrita de alcance nacional, durante o período 2008-2017, confirmamos a tendência de agudização do sector da imprensa escrita em papel, a partir da constatação de um cenário de queda continuada do volume de vendas. Criamos também um novo índice de eficiência para cálculo da força das publicações no mercado, e, com base no cálculo da taxa de variação do número médio mensal de vendas para o período 2008-2017, chegamos ao ano de 2029 como data hipotética para o fim das vendas de jornais em papel em Portugal.
\end{abstract}

Palavras-chave: Imprensa em papel, Evolução da circulação impressa paga e tiragens, Índice de Eficiência das publicações, 2029, Portugal.

Abstract

\begin{abstract}
New digital products and new techniques tend to have a strong influence in the print media sector and in its traditional formats, as these new products and techniques become agents of incremental change (Küng, 2013; Storsul, 2013) and radical and disruptive innovation (Sádaba, 2016a, b, c), by interfering with users' conventional usage and consumption logics.

Several authors (Hjarvard, 2012, Barnhurst, 2010, Brock, 2015, Nossek et al., 2015) discuss the effects of technological mutability in the print media sector and in its traditional formats, pointing out almost unanimously to scenarios in which the sales of newspapers in the traditional format have been decreasing steadily over the years, in an Era of hyper-information and immediacy, and due to the rapid migration of news consumers to the online formats supported in multiformats, polycentrality and participation (Queuniet, 2011).

By analysing longitudinal data collected by the Portuguese Association for the Control of Circulation (APCT) on the major portuguese newspapers' sales and print circulation, during the period from 2008 to 2017, we outline a scenario of continued decline in the sales and circulation of newspapers. We also create a new efficiency index in order to calculate the strength of these newspapers in the market. On the other hand, and considering the calculation of the monthly average rate variation sales for the period from 2008 to 2017, we have established the year 2029 as a predicted date of the end of traditional print newspapers in Portugal.
\end{abstract}

Keywords: Print newspapers, Evolution of the paid and print circulation, Publications' efficiency index, 2029, Portugal.

\footnotetext{
${ }^{1}$ Este artigo foi escrito com o apoio financeiro da FCT (Fundação para a Ciência e Tecnologia - Portugal), contemplado na bolsa individual de doutoramento com a referência SFRH/BD/131338/2017
} 


\section{Introdução}

A migração dos públicos de notícias para os formatos digitais - onde as características da Internet potenciam híper-consumos em multiformato (Jenkins, 2006), policentralidade, participação (Fenton, 2010) e imediatismo (Karlsson, 2011) - trouxe novos e profundos desafios ao sector da imprensa escrita, ditando 1) um progressivo declínio da cultura da página impressa, outrora decisiva na Galáxia de Gutenberg (McLuhan, 1972) e 2) o declínio das estruturas de supervisão do fluxo informativo, com os utilizadores a disputarem a autoridade da prática jornalística nos conteúdos produzidos, nas opiniões e na disputa dos factos (Singer, 2010; Bruns, 2005; Deuze, 2005).

Este consumo em multiformato e policêntrico, fortemente sustentado nas lógicas de gratuitidade, veio interromper a tradicional hegemonia dos formatos tradicionais e das suas estruturas unidireccionais de disseminação e recepção de conteúdos noticiosos. Para além disso, os consumos heterogéneos exponenciados pelos sub-jornalismos (jornalismo participativo em rede) (Beckett, 2008, 2010; Lewis, 2012; Barnes, 2012; Singer et al., 2011) erguidos das dinâmicas de produção descentralizada, horizontal e colaborativa (Beckett, 2010), onde a esfera das redes sociais constitui uma dimensão de análise fulcral na interpretação das transformações das audiências de notícias, vieram antagonizar ainda mais o sector da imprensa escrita na sua variante impressa, disputando o seu papel histórico alavancado nas barreiras bem definidas entre o jornalismo credenciado e o receptor, até então passivo, do conteúdo informativo. Como nos recorda Steen Steensen (2016: 115), "o primeiro contacto com a notícia ocorre hoje mais nas redes sociais, do que via distribuidores tradicionais". A informação impressa cede assim a hegemonia do seu papel (histórico) aos consumos digitais e à voracidade do híper-consumo de conteúdos informativos na Era da sociedade em rede (Castells, 2002) e das culturas da conectividade (Van Dijck, 2013).

\section{Metodologia quantitativa por análises secundárias e estatísticas oficiais}

A análise quantitativa por análises secundárias via estatísticas oficiais deve, em primeiro lugar, ser vista como uma oportunidade. Uma oportunidade que encerra em si benefícios à investigação (Bryman, 2012: 312-313), tais como 1) a questão da agilização e racionalização de recursos (custos/tempo); 2) o facto de as estatísticas secundárias geralmente terem origem em processos de medição rigorosos (de longo alcance e com grande cobertura de regiões e populações) levados a cabo por organismos credenciados; 3) a oportunidade que estes dados oferecem no desenvolvimento de análises longitudinais; 4) a possibilidade de permitirem um detalhe maior na investigação; 5) a oportunidade de permitirem de forma mais recorrente análises transculturais; 6) a possibilidade de concederem mais tempo ao investigador para a análise dos dados, precisamente porque a obtenção de dados próprios pode ser fastidiosa; e 7) pelo facto de a utilização complementar de análises secundárias por estatísticas oficiais poder oferecer novas interpretações sobre o objecto de estudo.

Para elaboração deste artigo, que pretende debruçar-se sobre as características da imprensa portuguesa tradicional em papel, utilizámos dados secundários de instituições públicas como a Associação Portuguesa para o Controlo de Tiragem e Circulação (APCT), e dados do último inquérito Digital News Report, 2018, que resultam de uma colaboração entre o Observatório da Comunicação de Lisboa e o Reuters Institute for 
the Study of Journalism, colaboração essa que consistiu na aplicação de um inquérito a 2008 inquiridos utilizadores de Internet a partir de uma amostra probabilística proporcional e representativa da população portuguesa.

Os dados APCT, fulcrais na elaboração deste artigo, visam conhecer para o período $2008-2017^{2}$ as dinâmicas do sector a partir da leitura do volume de tiragens e circulação impressa paga do conjunto de títulos de imprensa com publicação impressa que mais se destacam em Portugal, pelo seu alcance e peso no sistema mediático português, a saber: Correio da Manhã, Jornal de Notícias, Diário de Notícias, Público, i, Expresso, Sol, Visão, Sábado, Diário Económico, Jornal de Negócios, Jornal Económico, Record, O Jogo, e Courrier Internacional. Desta lista de jornais, importa salientar que o jornal i deixou de facultar leituras à APCT no ano de 2015, assim como o semanário O Sol em 2016. O jornal Diário Económico fechou portas em 2016 e o Jornal Económico foi fundando no mesmo ano.

A partir dos dados APCT, as leituras sobre Circulação Impressa Paga (CIP) e Tiragens permitem-nos criar o Índice de Eficiência das Publicações que nos possibilita compreender, intra-publicação, os ajustamentos para o ano seguinte no volume de tiragens, em função do número de exemplares vendidos no ano exactamente anterior, como forma de reajuste, por parte dos grupos detentores das várias publicações, à procura e aos custos de produção. A partir destes dados, fazemos uma projecção para o fim hipotético da imprensa escrita em papel em Portugal, com base nas taxas de variação do número de exemplares em papel vendidos ao longo dos 10 últimos anos (2008-2017).

Para efeitos de aproximação das leituras à realidade, e para o caso concreto das publicações i e semanário O Sol, contabilizamos o mesmo volume de tiragens e CIP indicados para o ano em que se realiza a última contagem pela APCT, com o objectivo de não enviesar os argumentos apresentados para os anos posteriores, mesmo sabendo que, tendencialmente, o número de exemplares vendidos diminui todos os anos. Em relação ao jornal o Diário Económico, a última leitura será o ano de 2016, ano em que entra em circulação o novo Jornal Económico que também será contabilizado e que tem uma circulação mais ou menos semelhante ao Diário Económico extinto no mesmo ano.

Os dados extraídos do relatório Digital News Report, do Reuters Institute (2018), irão enquadrar questões como a frequência de consulta de notícias.

\section{Imprensa escrita em papel, um sector em constante agudização}

A leitura de jornais pagos, assim como as receitas daí provenientes, estão há décadas em declínio na maioria dos países ocidentais, e ainda não foi encontrado nenhum modelo de negócio viável para as notícias na Era dos media digitais (Hjarvard, 2012). Os utilizadores de Internet e de plataformas móveis não estão à partida susceptíveis a pagar por notícias (Hjarvard, 2012: 99), no sentido em que, com a migração dos públicos para o digital, o consumo de notícias passou a estruturar-se nas lógicas de gratuitidade híper-mediada, descurando o formato físico, com implicações para o sector da imprensa em papel. Isto coloca uma pressão adicional ao sector da imprensa escrita, uma vez que se torna necessário reduzir os custos associados à

\footnotetext{
2 Este período é particularmente importante na análise das grandes transformações do tecido social português, com impacto nos mercados de trabalho e nas indústrias de produção, por representar um período em que Portugal passa pelo impacto da crise do subprime e das dívidas soberanas, assim como por um período alargado de processos de ajustamento e de austeridade.
} 
produção de notícias no formato tradicional, ao mesmo tempo que se investe em novas plataformas de produção e disseminação de notícias, sem qualquer perspectiva de viabilidade (Hjarvard, 2012: 99).

A ideia de que o sector da imprensa escrita tradicional é o mais afectado pela mudança tecnológica é uma ideia que encontra as suas raízes no desenvolvimento da sociedade em rede (Castells, 2002), nas estruturas de compressão de espaço e distância (Martell, 2017; Giddens, 1991, 2000) e na interconectividade multidimensional das tecnologias que transformaram a forma como comunicamos (Pavlik, 1997).

A este processo de mudança tecnológica e dos (novos) paradigmas comunicacionais sustentados na Internet, e à sua repercussão no sector dos media, Fidler (1997) designou como Mediamorfose, processo moldado pelas estruturas de transformação comunicacional nos media e nas formas de produção e consumo de conteúdos produzidos (González, 2017; Freire, 2011). O domínio digital traduz-se na grande transformação da comunicação humana desde a linguagem escrita, e a propagação dos media digitais online mudou radicalmente, por exemplo, a profissão e a actividade do jornalista, na sua forma e formatos de produção tradicionais e nas formas como eram conhecidos (Deuze, 2007). Por outras palavras, e como refere Flávian (2006, 231), "a indústria dos jornais está entre os sectores mais afectados pelo desenvolvimento dos canais electrónicos".

Discutindo sobre os processos de transição, Barnhurst (2010: 1083) lembra-nos que, no início do século XXI, com a maturidade da Internet 1.0. e o carácter embrionário da Internet 2.0., os jornais online eram ainda uma novidade não lucrativa, e muitos editores preferiam ainda a rotina da publicação impressa. Contudo, esta era já uma fase em que os jornalistas passavam cada vez mais tempo a reunir informação disponível na Internet, sendo que as mudanças nas notícias, na sua dimensão de produção/recepção, acompanharam mudanças no poder da imprensa e dos jornalistas (Barnhurst e Nerone, 2001). Com o advento da Internet, as práticas jornalísticas viram grandes transformações (Gronemeyer, 2013), não só com a intensa mutabilidade tecnológica (Fenton, 2010), mas também com a entrada dos novos agentes que passaram a fragmentar-se e a poder escolher e a poder participar nos processos de produção em rede (Benkler, 2006; Van den Bulck, 2018: 11). Com esta redefinição das barreiras entre produtor e consumidor de conteúdos (Singer, 2008; Shoemaker, 2009; Beckett, 2010; Van der Haak, 2012), e com a migração das audiências para o formato online, a imprensa em papel perdeu volume, centralidade e sustentabilidade, e os jornais começaram a perder milhares de empregos, fecharam portas ou entraram no domínio online por completo (Barnhurst, 2010: 1083).

Tanikawa (2017: 3519) refere que foram as características estilística, funcional e física dos jornais impressos, que resultaram na perda da sua capacidade em divulgar conteúdos e notícias novos, perdendo a batalha para o imediatismo da informação instantânea online que arrastou consigo as grandes audiências.

Brock (2015), por seu turno, observa que a crise no jornalismo e imprensa escrita é uma ideia antiga, que remonta aos anos 20 e 30 do século passado, com o surgimento da rádio e, mais tarde, com o surgimento da televisão. Para o autor, a crise dos jornais está assim longe de ser um fenómeno recente.

Por outro lado, num artigo com a chancela Columbia Journalism Review³, onde se discute a visão de Fidler (tido como o pai do jornalismo digital) para o futuro das notícias, argumenta-se que as notícias e fluxo informativo, na visão de Fidler, iriam migrar na sua plenitude para a internet, onde as histórias seriam instantaneamente publicadas e disseminadas de um computador para milhões de pessoas, eliminando a necessidade de operar um dispendioso media gerido por trabalhadores também eles dispendiosos. Contudo,

\footnotetext{
${ }^{3}$ https://www.cjr.org/special_report/print_analog_comeback.php
} 
mais tarde, adianta o mesmo artigo, Fidler reconheceu que replicar a impressão a partir de um dispositivo digital e no formato online é muito mais difícil do que alguém poderia inicialmente prever. Igualmente preocupado com a experiência de leitura e a economia de todas as formas de produção noticiosa online, onde a questão da distracção e desmobilização via conteúdo publicitário era tida como um exemplo, Fidler argumentava que o focus generalizado nos formatos online, por parte das organizações noticiosas, matava a imprensa escrita em papel e o seu produto principal.

Neste seguimento, para Nossek (et al., 2015), a ideia de que os jornais no formato físico estão a morrer, não é uma ideia exacta, na medida em que os media impressos constituem ainda uma importante componente do novo ecossistema comunicacional, o que fica a dever-se, sobretudo, à resiliência das publicações em formato físico. Nossek (et al., 2015), citando Sparks (1996), introduz alguma controvérsia na discussão sobre o futuro da impressa tradicional, referindo que "quase todos os cidadãos que têm em consideração as potencialidades das democracias no mundo contemporâneo percebem que os meios de comunicação, e os jornais em particular, têm um papel indispensável" (Sparks, 1996: 43, apud Nossek et al, 2015: 366). A esta função social positiva dos jornais, Sparks (1996) chamou de função de esclarecimento público.

Para Sparks (1996), as versões online dos jornais não conseguem assim fornecer a mesma função de esclarecimento público como os media impressos, devido às lacunas de acessibilidade (associada em parte à dimensão das literacias digitais) e diferenças na oferta de conteúdos.

Para além de Nossek (2015), outros autores, como o jornalista Jannarone (2014), decidem posicionar-se no lado mais optimista da discussão. Jannarone, no seu artigo de opinião intitulado "Read all about it: Print newspapers to survive! ${ }^{\prime 4}$, refere que, apesar de os jornais do futuro poderem vir a privilegiar na sua grande maioria o formato digital, os jornais no formato físico continuarão a existir porque haverá sempre consumidores que preferem o papel aos tablets e aos smartphones.

\section{Análise de dados secundários sobre o comportamento do sector da imprensa escrita em papel, em Portugal}

A análise aos dados extraídos dos boletins informativos da APCT, para 15 publicações ${ }^{5}$, denunciam um panorama nada animador para o sector da imprensa escrita em papel, em Portugal. A figura 1 convida-nos desde logo a uma reflexão sobre a intensidade do volume de perdas do número de jornais impressos vendidos. Com efeito, em 2008, o número de exemplares médios vendidos por mês situava-se nos 787.482. Em 2016, este valor passa pela primeira vez a ser menor do que o meio milhão de exemplares vendidos por mês, registando em 2017 o seu valor mais baixo (418.864).

A tendência dos valores registados demonstra que a queda do número de jornais impressos vendidos tem sido progressiva, com um declive bastante acentuado a partir do ano de 2011, o ano em que Portugal começou a ser intervencionado pela Troika ${ }^{6}$ e período no qual todo o tecido social português fica refém das medidas de austeridade, com impacto nos salários e no poder de compra dos cidadãos.

\footnotetext{
${ }^{4}$ https://www.cnbc.com/2014/10/03/read-all-about-it-print-newspapers-to-survive.html

${ }^{5}$ Correio da Manhã, Jornal de Notícias, Diário de Notícias, Público, i, Expresso, Sol, Visão, Sábado, Diário Económico, Jornal de Negócios, Jornal Económico, Record, O Jogo, e Courrier Internacional.

${ }^{6}$ Comissão Europeia, o BCE e o FMI
} 
Em termos percentuais, a queda do volume de jornais vendidos em Portugal entre os anos de 2008 e 2017 consubstancia-se num decréscimo de cerca de $47 \%$ do volume total de vendas registadas em relação ao primeiro ano em análise (2008), o que significa que, em dez anos, o número médio de jornais vendidos mensalmente é reduzido quase a metade.

Por outro lado, e apesar de a economia portuguesa ter começado a registar uma ligeira subida no ano de 20167 , a melhoria dos indicadores económicos do país não resultou num aumento indirecto do número de jornais vendidos no ano de 2017. Por outras palavras, apesar de o comportamento da economia portuguesa ter oscilado positivamente a partir de 2016 , os valores de venda de jornais continuaram a cair.

Figura 1: Evolução anual total da Circulação Impressa Paga8

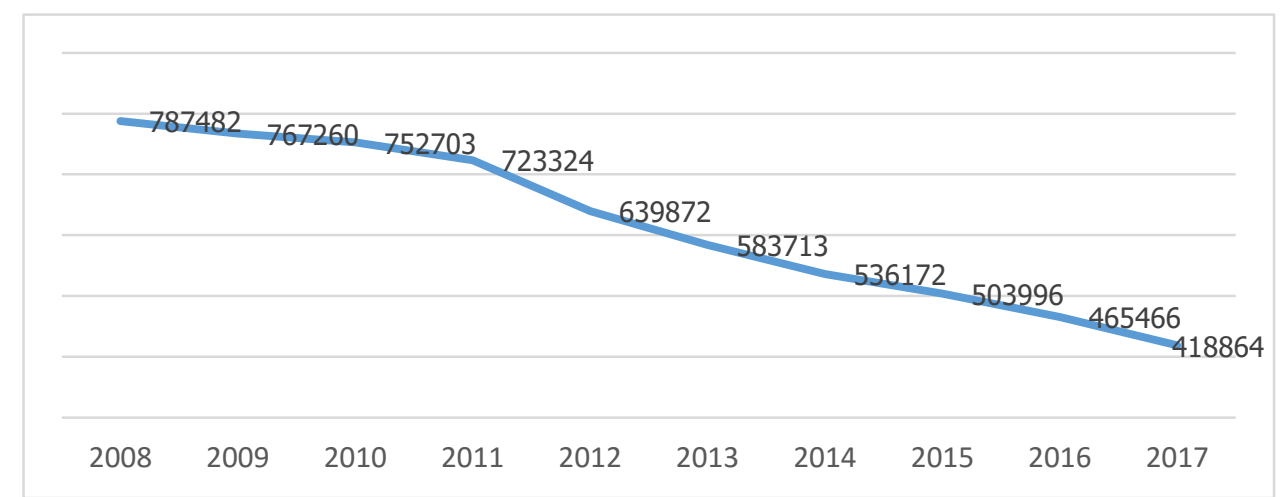

Fonte: APCT-Boletim Informativo Jan/Dez (2008-2017). Elaboração própria.

Analisando os dados obtidos para as várias publicações em análise, podemos observar que, para o período de dez anos (2008-2017), todas as publicações registam quedas substanciais do número de exemplares vendidos.

Até 2011, contudo, há algumas oscilações positivas no número de exemplares vendidos de algumas publicações que reforçaram esporadicamente, e com diferentes acentuações, o seu exercício de vendas, como é o caso do Correio da Manhã, Visão, Sábado, Diário Económico e Jornal de Negócios em 2009; Correio da Manhã, Visão, Diário Económico e Courrier Internacional em 2010; Jornal de Notícias, Diário de Notícias e Jornal de Negócios em 2011. A partir do ano de 2011, as únicas oscilações positivas registam-se na publicação Courrier Internacional.

Tabela 1: Evolução da Circulação Impressa Paga

\begin{tabular}{|c|c|c|c|c|c|c|c|c|c|c|}
\hline & 2008 & 2009 & 2010 & 2011 & 2012 & 2013 & 2014 & 2015 & 2016 & 2017 \\
\hline Correio da Manhã & 118353 & 118399 & 125417 & 125342 & 120330 & 114712 & 111031 & 105521 & 97044 & 87215 \\
\hline Jornal de Notícias & 101205 & 89007 & 84670 & 85325 & 72791 & 64192 & 58249 & 53877 & 49594 & 45662 \\
\hline Diário de Notícias & 39992 & 32771 & 29374 & 34119 & 27748 & 20025 & 15087 & 13558 & 11842 & 9893 \\
\hline Público & 42345 & 37276 & 34062 & 33159 & 27310 & 23672 & 21652 & 20470 & 18111 & 17990 \\
\hline I & ----- & 12828 & 9467 & 8211 & 5510 & 5089 & 4104 & 4104 & 4104 & 4104 \\
\hline Expresso & 119875 & 111669 & 108923 & 103652 & 90794 & 86143 & 78818 & 77812 & 73658 & 67109 \\
\hline
\end{tabular}

\footnotetext{
${ }^{7} \mathrm{https} / /$ www.jornaldenegocios.pt/economia/conjuntura/detalhe/economia-portuguesa-cresceu-14-em-2016

${ }^{8}$ Circulação Impressa Paga $=$ Soma das assinaturas + vendas + vendas em bloco
} 


\begin{tabular}{|c|c|c|c|c|c|c|c|c|c|c|}
\hline Sol & 46759 & 44373 & 41970 & 33089 & 27982 & 23684 & 23061 & 19625 & 19625 & 19625 \\
\hline Visão & 100201 & 100904 & 101635 & 96699 & 87249 & 81718 & 72993 & 69697 & 61609 & 55841 \\
\hline Sábado & 74194 & 77715 & 74846 & 72425 & 64833 & 59666 & 53702 & 48440 & 42571 & 40296 \\
\hline Diário Económico & 13686 & 14623 & 15605 & 14772 & 13251 & 10199 & 9868 & 7200 & 6343 & \\
\hline Jornal de Negócios & 8574 & 9694 & 9521 & 9533 & 8650 & 7781 & 6616 & 6019 & 5491 & 5014 \\
\hline Jornal Económico & & & & & & & & & 4278 & 1470 \\
\hline Record & 71889 & 70903 & 69554 & 62245 & 54942 & 50200 & 45895 & 43477 & 39209 & 33834 \\
\hline O Jogo & 31643 & 29021 & 28953 & 27457 & 22709 & 21482 & 20248 & 18497 & 17426 & 16024 \\
\hline Courrier Internacional & 18766 & 18077 & 18706 & 17296 & 15773 & 15150 & 14848 & 15699 & 14561 & 14787 \\
\hline Totais & 787482 & 767260 & 752703 & 723324 & 639872 & 583713 & 536172 & 503996 & 465466 & 418864 \\
\hline
\end{tabular}

Fonte: APCT-Boletim Informativo Jan/Dez (2008-2017). Elaboração própria.

Tabela 2: Evolução da Circulação Impressa Paga (\%, taxa de variação anual)

\begin{tabular}{|c|c|c|c|c|c|c|c|c|c|c|}
\hline & 2008 & 2009 & 2010 & 2011 & 2012 & 2013 & 2014 & 2015 & 2016 & 2017 \\
\hline Correio da Manhã & & 0,04 & 5,9 & $-0,1$ & $-4,0$ & $-4,7$ & $-3,2$ & $-5,0$ & $-8,0$ & $-10,1$ \\
\hline Jornal de Notícias & & $-12,1$ & $-4,9$ & 0,8 & $-14,7$ & $-11,8$ & $-9,3$ & $-7,5$ & $-7,9$ & $-7,9$ \\
\hline Diário de Notícias & & $-18,1$ & $-10,4$ & 16,2 & $-18,7$ & $-27,8$ & $-24,7$ & $-10,1$ & $-12,7$ & $-16,5$ \\
\hline Público & & $-12,0$ & $-8,6$ & $-2,7$ & $-17,6$ & $-13,3$ & $-8,5$ & $-5,5$ & $-11,5$ & $-0,7$ \\
\hline I & & & $-26,2$ & $-13,3$ & $-32,9$ & $-7,6$ & $-19,4$ & 0,0 & 0,0 & 0,0 \\
\hline Expresso & & $-6,8$ & $-2,5$ & $-4,8$ & $-12,4$ & $-5,1$ & $-8,5$ & $-1,3$ & $-5,3$ & $-8,9$ \\
\hline Sol & & $-5,1$ & $-5,4$ & $-21,2$ & $-15,4$ & $-15,4$ & $-2,6$ & $-14,9$ & 0,0 & 0,0 \\
\hline Visão & & 0,7 & 0,7 & $-4,9$ & $-9,8$ & $-6,3$ & $-10,7$ & $-4,5$ & $-11,6$ & $-9,4$ \\
\hline Sábado & & 4,7 & $-3,7$ & $-3,2$ & $-10,5$ & $-8,0$ & $-10,0$ & $-9,8$ & $-12,1$ & $-5,3$ \\
\hline Diário Económico & & 6,8 & 6,7 & $-5,3$ & $-10,3$ & $-23,0$ & $-3,2$ & $-27,0$ & $-11,9$ & \\
\hline Jornal de Negócios & & 13,1 & $-1,8$ & 0,1 & $-9,3$ & $-10,0$ & $-15,0$ & $-9,0$ & $-8,8$ & $-8,7$ \\
\hline Jornal Económico & & & & & & & & & & $-65,6$ \\
\hline Record & & $-1,4$ & $-1,9$ & $-10,5$ & $-11,7$ & $-8,6$ & $-8,6$ & $-5,3$ & $-9,8$ & $-13,7$ \\
\hline O Jogo & & $-8,3$ & $-0,2$ & $-5,2$ & $-17,3$ & $-5,4$ & $-5,7$ & $-8,6$ & $-5,8$ & $-8,0$ \\
\hline Courrier Internacional & & $-3,7$ & 3,5 & $-7,5$ & $-8,8$ & $-3,9$ & $-2,0$ & 5,7 & $-7,2$ & 1,6 \\
\hline Totais & & $-2,6$ & $-1,9$ & $-3,9$ & $-11,5$ & $-8,8$ & $-8,1$ & $-6,0$ & $-7,6$ & $-10,0$ \\
\hline
\end{tabular}

Fonte: APCT-Boletim Informativo Jan/Dez (2008-2017). Elaboração própria.

Nota: O Jornal i e o semanário Sol deixaram de facultar leituras de CIP nos anos de 2015 e 2016, respectivamente.

O número de subidas no número de exemplares vendidos anualmente regista um total de 5 para o ano de 2009, 4 em 2010, 3 em 2011, 1 em 2015 e 1 em 2017. Todas as restantes 111 entradas são caracterizadas por descidas em vendas.

No que diz respeito à observação da evolução da circulação impressa paga para o total das publicações analisadas, e com base no cálculo das taxas de variação anual, podemos constatar que, apesar de todos os anos apresentarem taxas de variação negativa, é a partir de 2011 que estes valores negativos mais se acentuam, a partir de dois focos principais, primeiro no ano de 2012 e depois novamente a partir de 2016. 
Figura 2: Evolução da Circulação Impressa Paga total (taxa de variação anual)

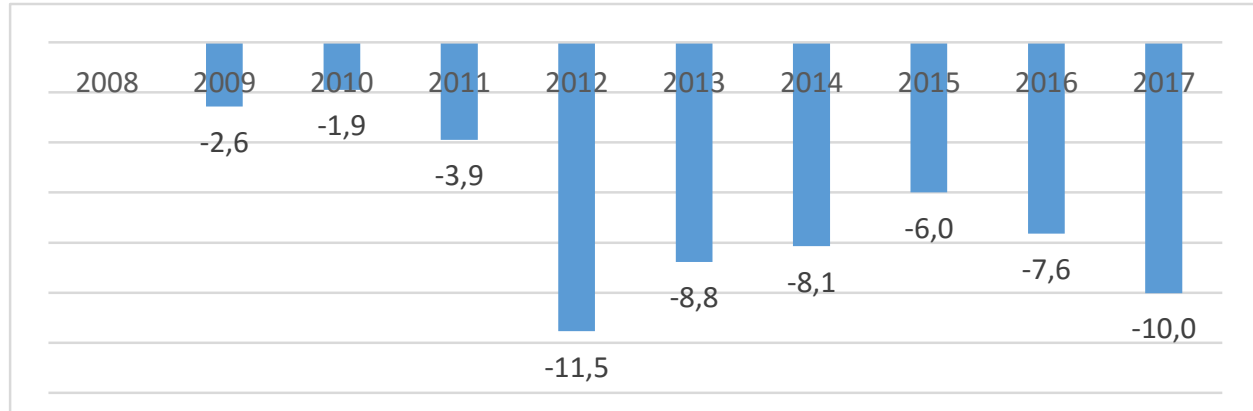

Fonte: Elaboração própria a partir de: APCT-Boletim Informativo Jan/Dez (2008-2017).

Em relação aos números globais registados para as tiragens, e como resultado das estratégias de ajuste dos vários grupos e títulos de imprensa, observamos uma queda semelhante à registada para o volume de circulação impressa paga.

Figura 3: Evolução anual das Tiragens

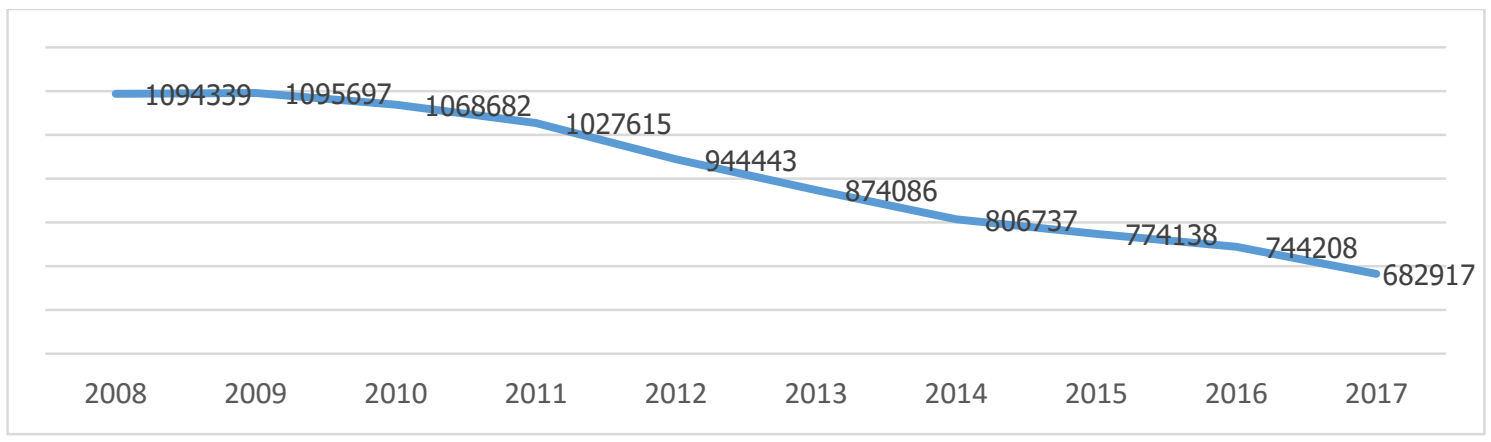

Fonte: APCT-Boletim Informativo Jan/Dez (2008-2017). Elaboração própria.

No período entre 2008 e 2017, o volume médio mensal de exemplares impressos em circulação caiu de 1.094.339 em 2008 para 682.917 em 2017 (valor mais baixo), queda essa que se traduz em menos 37,6\% de exemplares colocados em circulação, como resposta dos grupos em fazer face a uma queda do número médio mensal de exemplares vendidos na ordem dos $47 \%$, durante o mesmo período. A diminuição do volume de tiragens visa dar resposta e permitir o ajuste no número de exemplares colocados em circulação, com base no exercício de vendas registado para o ano imediatamente anterior. Este decréscimo do volume de tiragens visa essencialmente ajustar a estratégia das diferentes publicações à dimensão de procura no mercado e racionalizar os custos de produção em função dessa mesma procura.

Relativamente às leituras para a evolução global do número médio mensal de tiragens, a partir do cálculo das diferentes taxas de variação, verificamos um comportamento bastante semelhante àquele registado para a evolução da Circulação Impressa Paga, com dois picos de queda a estar associados aos anos de 2012 e 2017. 
Figura 4: Evolução global anual das Tiragens (taxa de variação anual)

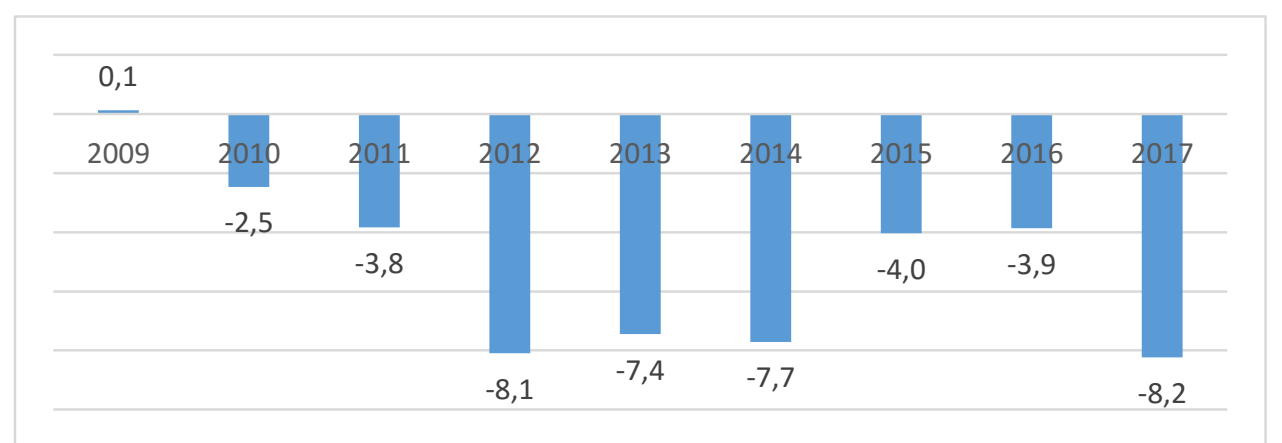

Fonte: Elaboração própria a partir de: APCT-Boletim Informativo Jan/Dez (2008-2017).

Os períodos que decorrem entre os anos de 2011 e 2012, e 2016 e 2017, são aqueles que registam uma queda mais acentuada no volume médio mensal de tiragens dos títulos de imprensa considerados na análise.

Tabela 3: Evolução anual das Tiragens de cada publicação

\begin{tabular}{|c|c|c|c|c|c|c|c|c|c|c|}
\hline & 2008 & 2009 & 2010 & 2011 & 2012 & 2013 & 2014 & 2015 & 2016 & 2017 \\
\hline $\begin{array}{l}\text { Correio da } \\
\text { Manhã }\end{array}$ & 156901 & 157616 & 164658 & 166673 & 161581 & 157167 & 153715 & 149605 & 141906 & 130067 \\
\hline $\begin{array}{l}\text { Jornal de } \\
\text { Notícias }\end{array}$ & 129850 & 116435 & 112774 & 111316 & 99557 & 91185 & 83467 & 77475 & 67887 & 65003 \\
\hline $\begin{array}{l}\text { Diário de } \\
\text { Notícias }\end{array}$ & 60420 & 50882 & 47384 & 51375 & 44744 & 37170 & 30825 & 28408 & 25929 & 23507 \\
\hline Público & 61924 & 54151 & 50190 & 48399 & 44279 & 42011 & 35078 & 34007 & 33070 & 32650 \\
\hline $\bar{i}$ & & 40214 & 25519 & 20445 & 17009 & 13724 & 12115 & 12115 & 12115 & 12115 \\
\hline Expresso & 148815 & 140006 & 134677 & 130600 & 114929 & 111079 & 99277 & 98511 & 94452 & 88788 \\
\hline Sol & 72276 & 67139 & 75056 & 61449 & 54109 & 51537 & 50797 & 48373 & 48373 & 48373 \\
\hline Visão & 123577 & 128276 & 122285 & 116494 & 110725 & 102691 & 90378 & 87738 & 81454 & 76146 \\
\hline Sábado & 99233 & 109657 & 108396 & 107151 & 100611 & 90028 & 84377 & 75884 & 68476 & 65055 \\
\hline $\begin{array}{c}\text { Diário } \\
\text { Económico }\end{array}$ & 21972 & 24333 & 23243 & 19392 & 18595 & 17281 & 16837 & 14476 & 13871 & \\
\hline $\begin{array}{l}\text { Jornal de } \\
\text { Negócios }\end{array}$ & 16642 & 18073 & 16964 & 17351 & 16323 & 13701 & 12629 & 12603 & 13690 & 12507 \\
\hline $\begin{array}{c}\text { Jornal } \\
\text { Económico }\end{array}$ & & & & & & & & & 12631 & 10825 \\
\hline Record & 115568 & 113177 & 113036 & 105322 & 97814 & 86580 & 81377 & 80179 & 78250 & 67811 \\
\hline O Jogo & 57825 & 50538 & 49658 & 48156 & 42550 & 38374 & 35257 & 32599 & 31237 & 29587 \\
\hline $\begin{array}{c}\text { Courrier } \\
\text { Internacional }\end{array}$ & 29336 & 25200 & 24842 & 23492 & 21617 & 21558 & 20608 & 22165 & 20867 & 20483 \\
\hline Totais & $\begin{array}{c}109433 \\
9\end{array}$ & $\begin{array}{c}109569 \\
7\end{array}$ & $\begin{array}{c}106868 \\
2\end{array}$ & $\begin{array}{c}102761 \\
5\end{array}$ & 944443 & 874086 & 806737 & 774138 & 744208 & 682917 \\
\hline
\end{tabular}

Fonte: APCT-Boletim Informativo Jan/Dez (2008-2017). Elaboração própria. 
De salientar novamente que o valor mais baixo entre todas as taxas de variação anual das tiragens médias mensais de cada publicação, é obtido em 2017, o último ano em análise.

Tabela 4: Evolução anual das Tiragens de cada publicação (taxa de variação anual)

\begin{tabular}{|c|c|c|c|c|c|c|c|c|c|c|}
\hline & 2008 & 2009 & 2010 & 2011 & 2012 & 2013 & 2014 & 2015 & 2016 & 2017 \\
\hline Correio da Manhã & & 0,5 & 4,5 & 1,2 & $-3,1$ & $-2,7$ & $-2,2$ & $-2,7$ & $-5,1$ & $-8,3$ \\
\hline Jornal de Notícias & & $-10,3$ & $-3,1$ & $-1,3$ & $-10,6$ & $-8,4$ & $-8,5$ & $-7,2$ & $-12,4$ & $-4,2$ \\
\hline Diário de Notícias & & $-15,8$ & $-6,9$ & 8,4 & $-12,9$ & $-16,9$ & $-17,1$ & $-7,8$ & $-8,7$ & $-9,3$ \\
\hline Público & & $-12,6$ & $-7,3$ & $-3,6$ & $-8,5$ & $-5,1$ & $-16,5$ & $-3,1$ & $-2,8$ & $-1,3$ \\
\hline $\mathrm{i}$ & & & $-36,5$ & $-19,9$ & $-16,8$ & $-19,3$ & $-11,7$ & 0,0 & 0,0 & 0,0 \\
\hline Expresso & & $-5,9$ & $-3,8$ & $-3,0$ & $-12,0$ & $-3,3$ & $-10,6$ & $-0,8$ & $-4,1$ & $-6,0$ \\
\hline Sol & & $-7,1$ & 11,8 & $-18,1$ & $-11,9$ & $-4,8$ & $-1,4$ & $-4,8$ & 0,0 & 0,0 \\
\hline Visão & & 3,8 & $-4,7$ & $-4,7$ & $-5,0$ & $-7,3$ & $-12,0$ & $-2,9$ & $-7,2$ & $-6,5$ \\
\hline Sábado & & 10,5 & $-1,1$ & $-1,1$ & $-6,1$ & $-10,5$ & $-6,3$ & $-10,1$ & $-9,8$ & $-5,0$ \\
\hline Diário Económico & & 10,7 & $-4,5$ & $-16,6$ & $-4,1$ & $-7,1$ & $-2,6$ & $-14,0$ & $-4,2$ & \\
\hline Jornal de Negócios & & 8,6 & $-6,1$ & 2,3 & $-5,9$ & $-16,1$ & $-7,8$ & $-0,2$ & 8,6 & $-8,6$ \\
\hline Jornal Económico & & & & & & & & & & $-14,3$ \\
\hline Record & & $-2,1$ & $-0,1$ & $-6,8$ & $-7,1$ & $-11,5$ & $-6,0$ & $-1,5$ & $-2,4$ & $-13,3$ \\
\hline O Jogo & & $-12,6$ & $-1,7$ & $-3,0$ & $-11,6$ & $-9,8$ & $-8,1$ & $-7,5$ & $-4,2$ & $-5,3$ \\
\hline Courrier Internacional & & $-14,1$ & $-1,4$ & $-5,4$ & $-8,0$ & $-0,3$ & $-4,4$ & 7,6 & $-5,9$ & $-1,8$ \\
\hline Totais & & 0,1 & $-2,5$ & $-3,8$ & $-8,1$ & $\begin{array}{l}-7,4 \\
\end{array}$ & $-7,7$ & $-4,0$ & $-3,9$ & $-8,2$ \\
\hline
\end{tabular}

Fonte: APCT-Boletim Informativo Jan/Dez (2008-2017). Elaboração própria.

Figura 5: Evolução das Tiragens e Circulação Impressa Paga

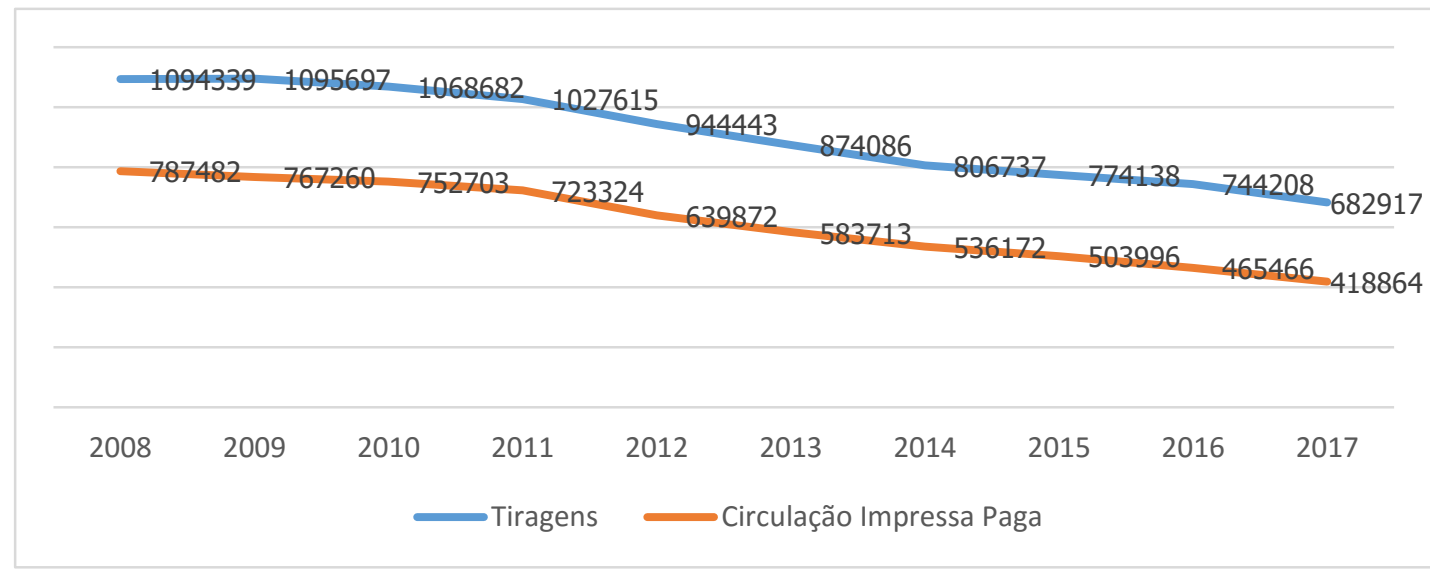

Fonte: APCT-Boletim Informativo Jan/Dez (2008-2017). Elaboração própria.

Ao analisarmos a figura 5, verificamos que o número de exemplares colocados em circulação tende a ser ditado pelo comportamento e desempenho das publicações em termos de venda, uma vez que a evolução destes dois indicadores tende a apresentar alguma semelhança na sua representação gráfica com base em declives semelhantes.

O Índice de Eficiência de Publicação agrega duas variáveis: circulação impressa paga e tiragem. Como referido anteriormente, este indicador tenta mensurar o excesso que decorre entre o volume de material 
impresso e o número de exemplares vendidos. Por outras palavras, o cálculo deste índice é feito de acordo com o rácio entre número de exemplares vendidos num determinado ano (Circulação Impressa Paga) e o número de tiragens. Quanto mais este valor se aproxima do 1, mais ideal se torna o cenário, uma vez que o contexto ideal é aquele em que tudo aquilo que é produzido consegue ser escoado no mercado, ou seja, vendido. Esta é a principal razão pela qual nos reportamos a este índice como índice de eficiência, uma vez que quanto menor for o excesso resultante das tiragens e das vendas, maior é a eficiência da publicação. Este índice representa os ajustes que são feitos pelos grupos de media detentores de publicações no formato em papel, relativamente ao comportamento no mercado das publicações, nos anos imediatamente anteriores à definição do número médio de tiragens para os anos seguintes.

A tabela 5 dá-nos uma visão geral da evolução deste índice ao longo de 10 anos. Para este cálculo, foram recuperados os valores referenciados nas Tabelas 1 e 3 deste artigo, num cálculo que é obtido a partir da divisão entre Circulação Impressa Paga e Tiragens.

Tabela 5: Evolução do Índice de Eficiência de Publicação, por publicação

\begin{tabular}{|c|c|c|c|c|c|c|c|c|c|c|}
\hline & 2008 & 2009 & 2010 & 2011 & 2012 & 2013 & 2014 & 2015 & 2016 & 2017 \\
\hline Correio da Manhã & 0,75 & 0,75 & 0,76 & 0,75 & 0,74 & 0,73 & 0,72 & 0,71 & 0,68 & 0,67 \\
\hline Jornal de Notícias & 0,78 & 0,76 & 0,75 & 0,77 & 0,73 & 0,70 & 0,70 & 0,70 & 0,73 & 0,70 \\
\hline Diário de Notícias & 0,66 & 0,64 & 0,62 & 0,66 & 0,62 & 0,54 & 0,49 & 0,48 & 0,46 & 0,42 \\
\hline Público & 0,68 & 0,69 & 0,68 & 0,69 & 0,62 & 0,56 & 0,62 & 0,60 & 0,55 & 0,55 \\
\hline i & & 0,32 & 0,37 & 0,40 & 0,32 & 0,37 & 0,34 & 0,34 & 0,34 & 0,34 \\
\hline Expresso & 0,81 & 0,80 & 0,81 & 0,79 & 0,79 & 0,78 & 0,79 & 0,79 & 0,78 & 0,76 \\
\hline Sol & 0,65 & 0,66 & 0,56 & 0,54 & 0,52 & 0,46 & 0,45 & 0,41 & 0,41 & 0,41 \\
\hline Visão & 0,81 & 0,79 & 0,83 & 0,83 & 0,79 & 0,80 & 0,81 & 0,79 & 0,76 & 0,73 \\
\hline Sábado & 0,75 & 0,71 & 0,69 & 0,68 & 0,64 & 0,66 & 0,64 & 0,64 & 0,62 & 0,62 \\
\hline Diário Económico & 0,62 & 0,60 & 0,67 & 0,76 & 0,71 & 0,59 & 0,59 & 0,50 & 0,46 & \\
\hline Jornal de Negócios & 0,52 & 0,54 & 0,56 & 0,55 & 0,53 & 0,57 & 0,52 & 0,48 & 0,40 & 0,40 \\
\hline Jornal Económico & & & & & & & & & 0,34 & 0,14 \\
\hline Record & 0,62 & 0,63 & 0,62 & 0,59 & 0,56 & 0,58 & 0,56 & 0,54 & 0,50 & 0,50 \\
\hline O Jogo & 0,55 & 0,57 & 0,58 & 0,57 & 0,53 & 0,56 & 0,57 & 0,57 & 0,56 & 0,54 \\
\hline Courrier Internacional & 0,64 & 0,72 & 0,75 & 0,74 & 0,73 & 0,70 & 0,72 & 0,71 & 0,70 & 0,72 \\
\hline Totais & 0,72 & 0,70 & 0,70 & 0,70 & 0,68 & 0,67 & 0,66 & 0,65 & 0,63 & 0,61 \\
\hline
\end{tabular}

Fonte: APCT-Boletim Informativo Jan/Dez (2008-2017). Elaboração própria.

Como podemos constatar, as leituras alargadas para o período que decorre entre 2008 e 2017 mostramnos que todos os índices de eficiência diminuem para as várias publicações, com duas excepções: 1) 0 Courrier Internacional, publicação que apresenta os resultados mais sustentáveis, também exemplificados em esporádicas subidas registadas para o número médio mensal de exemplares vendidos, como é o caso do ano de 2015; e 2) jornal i, cujos resultados pós-2014 são influenciados pelo facto de a sua direcção ter deixado de divulgar dados relativos ao número de vendas que são considerados por estimativa e com base no último resultado divulgado pelo grupo. 
Em resumo, este indicador é importante porque nos mostra a forma como algumas publicações conseguem ajustar de maneira mais eficiente o volume de exemplares impressos àquilo que é o comportamento do mercado e à dimensão de procura.

Em termos globais, tal como exemplificado na figura 6, o índice de eficiência global das publicações agregadas tem vindo a decrescer significativamente, especialmente depois do ano de 2011, o que atesta a ideia de que todas as quebras do número médio mensal de exemplares vendidos são superiores a qualquer estimativa feita pelos grupos detentores dos diferentes títulos de imprensa nas suas estratégias para os diferentes anos.

Figura 6: Evolução global do índice de Eficiência de Publicação

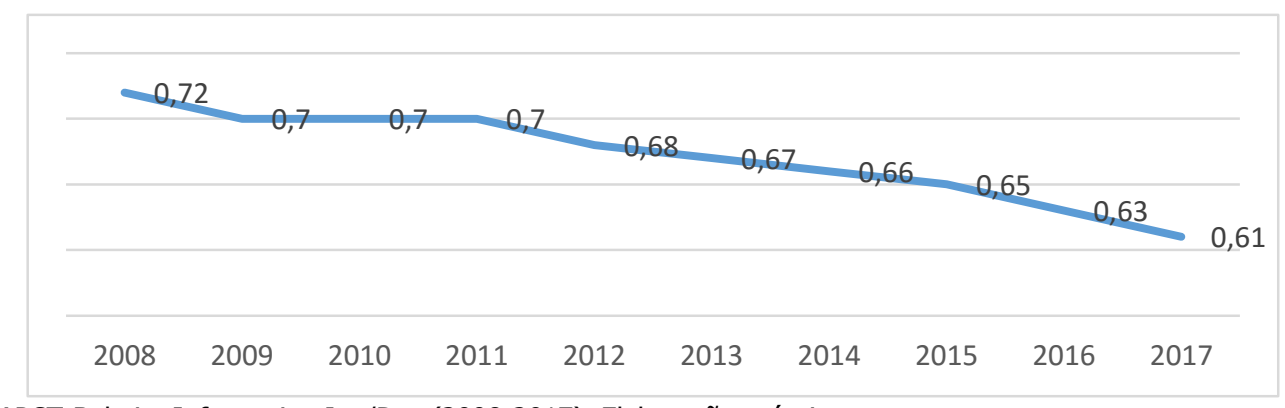

Fonte: APCT-Boletim Informativo Jan/Dez (2008-2017). Elaboração própria.

\section{O ano 2029}

Se, por exercício de curiosidade, considerarmos que o comportamento do sector da imprensa escrita tradicional em papel, durante os últimos dez anos (2008-2017), se irá manter para os anos subsequentes, numa taxa de variação negativa de $47 \%$ no número de vendas de jornais durante o período supramencionado, chegamos ao ano de 2029 como o ano em que a venda total de jornais das publicações agregadas consideradas neste estudo atingirá o valor nulo. Este seria então o ano em que as 15 publicações consideradas, todas juntas, deixariam de vender um único exemplar por mês. Apesar de este resultado ser meramente especulativo, uma vez que atribui um desempenho constante do sector no mercado, a proximidade desta derradeira data alerta-nos principalmente para a profunda vulnerabilidade de um sector que, todos os anos em Portugal, vê os seus indicadores de desempenho agravar-se. Para o sector da imprensa escrita em papel, o forte desequilíbrio e agudização consubstanciados nos valores discutidos é sobretudo o resultado das grandes migrações das audiências interactivas e participativas para o formato digital, numa Era de híper-informação online (Andrejevic, 2013) que condiciona estratégias de monetização dos grupos detentores de títulos de imprensa paga em papel. 
Figura 7: Projecção Circulação Impressa Paga $=0$

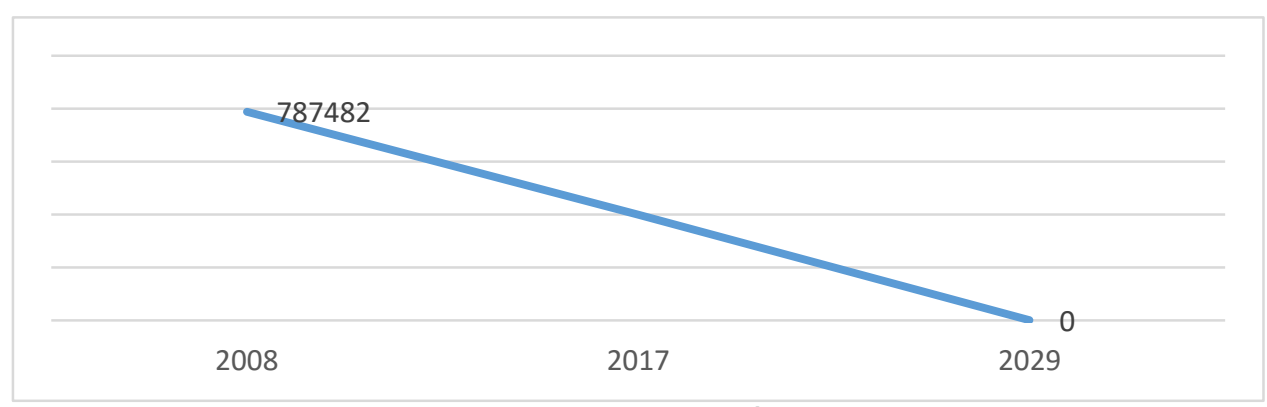

Fonte: APCT-Boletim Informativo Jan/Dez (2008-2017). Elaboração própria.

\section{O enfraquecimento do formato tradicional em papel como consequência do crescimento online da consulta de notícias}

Uma forma de avaliar as motivações dos consumidores de notícias, no que respeita à dimensão de compra de jornais, passa por analisar o módulo sobre apropriação de notícias do Digital News Report de 2018. Os dados extraídos deste inquérito mostram-nos que, em Portugal, cerca de $68 \%$ dos inquiridos utilizadores de Internet não compraram qualquer jornal no formato impresso, na semana anterior à realização do inquérito.

Figura 8: "Comprou algum jornal no formato impresso, na semana anterior?"

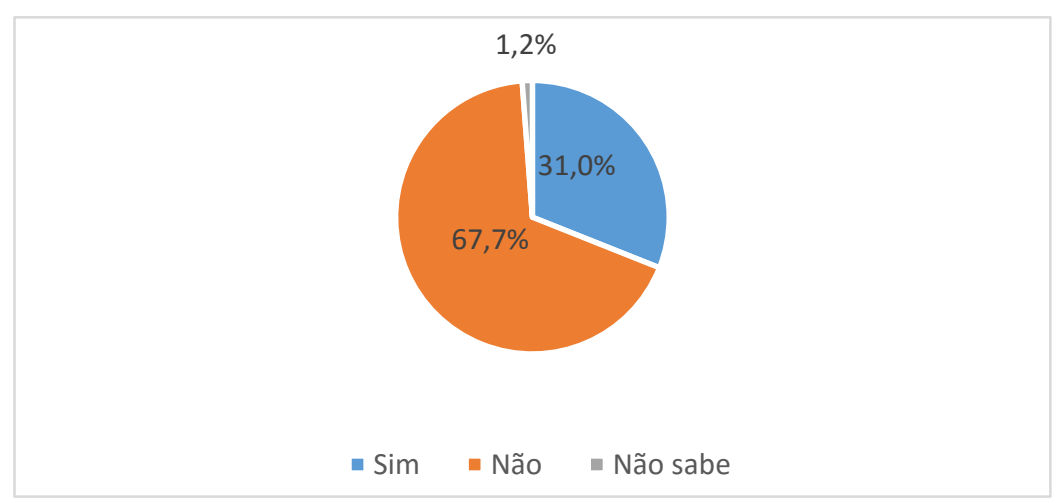

Fonte: Digital News Report, 2018, n=2008. Reuters Institute. Elaboração própria.

Por outro lado, e apesar de 91,2\% dos utilizadores de Internet envolvidos no estudo do Reuters Institute for the Study of Journalism considerarem que consultam notícias pelo menos uma vez por dia, 89,2\% do total da amostra declara não ter pago por qualquer conteúdo noticioso online, o que evidencia um traço distintivo dos utilizadores portugueses de notícias que passaram a privilegiar nas suas dietas informativas a consulta gratuita de conteúdos informativos no formato online, numa dinâmica que se distancia da consulta de notícias no formato físico, historicamente associada à compra do jornal. 


\section{Conclusões}

Apesar de termos confirmado que, em Portugal, as vendas de jornais impressos têm assistido a um declínio continuado promovido pela migração em grande escala dos públicos de notícias para os domínios online em multiformato, policentralidade, interacção e participação, alguns autores (Nossek, 2015) reconhecem o facto de esta não ser uma discussão que se esgota na irrevogabilidade do fatalismo e pessimismo hegemónicos associados ao futuro da imprensa escrita tradicional. Para alguns autores, a imprensa escrita no formato físico continuará sempre a existir pela sua simbiose com o ideal normativo de construção democrática sustentado nas estruturas do jornalismo credenciado e sua função social positiva (Nossek, 2015; Sparks, 1996), e pelo simples facto de que existirá sempre um número significativo de leitores que preferem o papel ao formato digital (Jannarone, 2014).

Para além disso, apesar de a mudança tecnológica afectar a imprensa escrita tradicional a um nível que não é sentido por muitas outras indústrias (Flávian, 2006), a cultura da página impressa, na qual o jornal no formato físico surge como o símbolo maior do homem tipográfico (Mcluhan, 1972), passa há quase um século por uma espécie de morte anunciada, primeiro com o surgimento da rádio, e, posteriormente, com o surgimento da televisão (Brock, 2015), o que introduz a ideia de que o fim da imprensa escrita em papel, na forma de axioma, não é um exclusivo da contemporaneidade.

Contudo, a corrente predominante na discussão do futuro da imprensa escrita tradicional passa por reconhecer que os jornais no formato físico migram e continuarão a migrar no futuro, na sua plenitude ou de forma preferencial, para os formatos digitais (Hjarvard, 2012; Barnhurst e Nerone, 2001; Tanikawa, 2017), o que explica o facto de o Diário de Notícias ${ }^{9}$, um dos 4 jornais de referência em Portugal, ter passado a existir desde Junho de 2018 (com excepção dos domingos) em versão exclusivamente online.

Da análise dos resultados para a circulação impressa paga, encontrámos um sector em profunda crise, com as taxas de variação do número médio mensal de exemplares vendidos por publicação a decrescer ao longo do período em análise, de tal forma que, se estivéssemos a falar de um sector com um desempenho de vendas constante no mercado, o número de jornais vendidos em 2029 seria igual a zero. A acompanhar o decréscimo das vendas de jornais, temos o volume de tiragens ou de exemplares em circulação que, resultando dos cálculos de ajustamento dos grupos detentores de jornais no formato em papel, a partir do exercício de vendas dos anos imediatamente anteriores àqueles em que se registam esses ajustamentos, representam também uma diminuição muito assinalável do volume de exemplares impressos colocados em circulação.

Os cálculos para as taxas de variação anual do número médio mensal de jornais vendidos e colocados em circulação registam também dois períodos de intensa queda dos valores registados: o ano de 2012, que assinala o primeiro aniversário do período de austeridade no pós-intervenção Troika em Portugal, e o ano de 2017, o último ano em análise.

Por outro lado, importa ressalvar que, de acordo com os resultados obtidos para o índice de eficiência de publicações que foi criado, resulta a ideia de que cada vez é mais difícil aos grupos detentores de títulos de imprensa no formato em papel, prever o comportamento das publicações para os diferentes anos que integram o ajuste do número de exemplares colocados em circulação em função do número de exemplares

\footnotetext{
9 https://www.publico.pt/2018/06/15/sociedade/noticia/diario-de-noticias-abandona-edicao-papel-a-semana-e-so-
} estara-nas-bancas-aos-domingos-1834437 
vendidos no ano anterior, uma vez que este índice de eficiência das publicações, salvo raras oscilações, como é o caso dos resultados obtidos para o Courrier Internacional, tem registado diminuições reveladoras, o que significa que o material não escoado ou o excedente entre material impresso e material vendido, é cada vez maior. Este excedente pode assim ser considerado como um sintoma mais de um sector em constante agudização.

Por último, ao utilizarmos os dados relativos ao último Reuters Digital News Report, 2018, cujos dados obtidos para o contexto português resultam de uma colaboração entre o Reuters Institute for the Study of Journalism e o OberCom, verificámos que não só a grande maioria dos utilizadores de Internet em Portugal declara não ter comprado qualquer jornal no formato físico na semana anterior à realização do inquérito, como uma mesma grande maioria tende a consultar conteúdos informativos pelo menos uma vez por dia sem pagar pelo acesso a notícias, o que evidencia o traço distintivo dos novos públicos de notícias em rede, orientados para a consulta em gratuitidade.

O decréscimo do número de vendas de jornais em formato físico parece ser o padrão em diferentes geografias (Saperstein, 2014; Bothum, 2016). Um estudo Pew Research Center (2017) mostra-nos que, por exemplo nos EUA, país com uma forte tradição no sector da imprensa escrita, a imprensa tradicional foi duramente atingida à medida que mais e mais americanos passaram a consumir notícias digitalmente. As receitas financeiras e a base de assinantes neste setor estão assim em declínio desde o início dos anos 2000. Assim, e como refere o estudo PwC assinado por Deborah Bothum (et al, 2016: 1), "em todo o mundo, os editores de jornais e revistas esforçam-se no sentido de uma adaptação aos desafios e oportunidades apresentados pela ruptura digital e suas mudanças económicas".

Contudo, esta forma determinística de olhar para o problema põe de parte as vantagens de uma análise transcultural, como aquela realizada para o caso português neste artigo. A ideia de que o sector da imprensa escrita tradicional se desenrola de forma padronizada, é uma ideia errónea que só é explicada à luz da forma determinística e ocidentalizada de olhar para o jornalismo e para a imprensa. Com efeito, e apesar de, no mundo ocidental, o jornal no formato físico ser hoje uma 'amostra' daquilo que foi outrora, em mercados como o da Índia, a consulta de jornais em papel tem crescido todos os anos, como nos mostram os dados do World Press Trends Database (2017), que assim reforçam a ideia de olhar para o sector da imprensa escrita de uma forma cuidada, crítica e descentrada.

\section{Referências Bibliográficas}

APCT, Boletim Informativo (Jan/Dez 2008-2017).

Barnhurst, K. G. (2010). Technology and the changing idea of news: 2001 U.S. newspaper contente at the maturity of Internet 1.0. In International Journal of Communication 4(2010). 1082-1099.

Barnhurst, K. G., \& Nerone, J. C. (1991). Design changes in U.S. front pages, 1885-1985. Journalism Quarterly 68 (4), 796-804. https://doi.org/10.1177/107769909106800420

Barnes, C. (2012). Citizen Journalism vs traditional journalism: a case of collaboration. JSTOR. Taylor and Francis.

Beckett, C. (2008), Super Media - Saving Journalism so it can save the world. Blackwell Publishing: USA.

Beckett, C. (2010), The Value of Networked Journalism. Polis Journalism and Society: London School of Economics and Political Science: UK. 
Benkler, Y. (2006). The wealth of networks: How social production transforms markets and freedom. Yale University Press.

Bothum, D., et al. (2016). Newspapers \& Magazines: transitioning from a print past to a digital future: triggering new strategies and wide divergences between markets. PwC. Disponível em: https://www.pwc.com/gx/en/entertainment-media/pdf/newspapers-and-magazines-outlookarticle.pdf

Brock, G. (2013). Out of Print: newspapers, journalism and the business of news in the Digital Age. London: Kogan Page Limited.

Bruns, A. (2005). Gatewatching: collaborative online news production. New York: Peter Lang.

Bryman, A. (2012). Social Research Methods. 4th edition. University of Oxford: Oxford University Press.

Castells, M. (2002). A Sociedade em Rede. Lisboa: Fundação Calouste Gulbenkian.

Columbia Journalism Review. Print is dead. Long live print. Disponível em: https://www.cjr.org/special_report/print_analog_comeback.php

Deuze, M. (2005). What is Journalism? Professional Identity and Ideology of Journalists Reconsidered. Journalism, 6/4: 442.64. Sage Publications. https://doi.org/10.1177/1464884905056815

Deuze, M. (2007). Media Work. Cambridge: Polity Press.

Fenton, N. (2010). "News in the Digital Age". In The Routledge Companion to News and Journalism. Routledge: UK. P557.

Fidler, R. F. (1997). Mediamorphosis: Understanding new media. London and New York: Sage.

Flavián, C. \& Gurrea, R. (2006). The Impact of the Internet on press sector: New possibilities of digital press versus traditional press. In Journal of Internet Banking and Commerce 11(3).

Freire, F. C. (2011). El nuevo Escenario Mediático. Comunicación social ediciones y publicaciones: Sevilla.

Giddens, A. (1991), The consequences of modernity. Polity Press: Cambridge.

Giddens, A. (2000). Runaway world. Routledge: New York.

González, A. L. \& Robles, F.A. (2017). Mediamorfosis. Perspectivas sobre la innovación en periodismo. XXIII Congreso Internacional de la Sociedad Española Periodística.

Gronemeyer, M.E. (2013). La Digitalización y sus efectos sobre las prácticas y produtos periodísticos en Chile. In Palabra Clave, vol6, no1. DOI: 10.5294/pacla.2013.16.1.4

Hjarvard, S. (2012). "The study of news production. "In Jensen, Klaus Bruhn (ed.). A Handbook of media and communication research: qualitative and quantitative methodologies. London and New York: Routledge.

Jannarone, J. (2014). Read all about it: Print newspapers to survive! In CNBC. Disponível em: https://www.cnbc.com/2014/10/03/read-all-about-it-print-newspapers-to-survive.html

Jenkins, H. (2006) Convergence Culture: Where Old and New Media Collide. New York University Press: New York.

Karlsson, M. (2011). The immediacy of online news, the visibility of journalistic processes and a restructuring of journalistic authority. In Journalism, vol12, issue 3. https://doi.org/10.1177/1464884910388223

Küng, L. (2013). "Innovation, Technology and Organisational Change. Legacy Media's Big Challenges. An Introduction". In Media Innovations: A multidisciplinary study of change. NORDICOM: University of Gothenburg. 
Lewis, S. C. (2012). The Tension between professional control and open participation: Journalism and its boundaries. In Information, Communication \& Society. Vol. 15, No 6. https://doi.org/10.1080/1369118X.2012.674150

Martell, L. (2017). The Sociology of Globalization. Polity Press: UK.

McLuhan, M. (1972). A Galáxia de Gutenberg: a formação do homem tipográfico. Companhia Editorial Nacional. Editora da Universidade de São Paulo.

Nossek, H. \& Adoni, H. \& Nimrod, G. (2015). Is Print Really Dying? The State of Print Media use in Europe. In International Journal of Communication 9, 365-385.

Pavlik, J. V. (1997). The Future of Online Journalism: A Guide to Who's Doing What. Columbia Journalism Review, Julho/Agosto.

Pew Research Center, 2017. Newspapers Fact Sheet. Consultado em 24 de Maio de 2018. Disponível em: http://www.journalism.org/fact-sheet/newspapers/

Queuniet, V., et al. (2011). Les entreprises de presse face aux évolutions numériques. Délégation Générale à L'emploi et à la formation professionnelle.

Sádaba, C. (2016), "La gestión de la innovación tecnológica en las empresas de medios: El caso de los "Labs", en VVAA La prensa digital en España, 2016, Institute for Media and Entertainment y Carat, Madrid; pp.139-148.

Sádaba, C. (2016), La innovación y los cibermedios: los labs. En Sádaba, Charo, García Avilés, José Alberto y Martínez Costa, Maria Pilar (coords) (2016), Innovación y desarrollo de los cibermedios en España, pp. 41-49, Eunsa, Pamplona.

Sádaba, C. (2016), Los 'labs' de medios en España: modelos y tendencias. En Casero-Ripollés, Andreu, Periodismo y democracia en el entorno digital, pp.149-164, Sociedad Española de Periodística, Salamanca.

Saperstein, T. (2014). The future of print: newspapers struggle to survive in the age of technology. Harvard Political Review. Disponível em: http://harvardpolitics.com/covers/future-print-newspapersstruggle-survive-age-technology/

Shoemaker, P. J. \& Vos, T.P. (2009). Gatekeeping Theory. New York: Routledge.

Singer, J. B. (2008). The journalist in the Network. A Shifting Rationale for the Gatekeeping Role and the Objectivity Norm. Tripodos 23, 61-76.

Singer, J. B. (2011). Participatory Journalism: Guarding Open Gates at Online Newspapers. Wiley-Blackwell: UK.

Singer, J. B. (2010). "Journalism in the Network". In The Routledge Companion to News and Journalism. Routledge: UK. P557.

Sparks, C. (1996). Newspapers, the Internet and democracy. Javnost-The Public, 3 (3), 43-57.

Steensen, S. (2016), The Intimization of Journalism, chapter 8, p115. In Hermida et al (ed) (2016), The Sage HandBook of Digital Journalism. London: Sage.

Storstul, T. \& Krumsvist, A. H. (2013). "What is Media Innovation?". In Media Innovations: A Multidisciplinary Study of Change. NORDICOM: University of Gothenburg.

Tanikawa, M. (2017). What Is News? What Is the Newspaper? The Physical, Functional, and Stylistic Transformation of Print Newspapers, 1988-2013. In International Journal of Communication. 11(2017), 3519-354. 
Van den Bulck, et al. (2018). Public Service Media in the networked society. What society? What Network? What Role? In Lowe, Gregory Ferrell, Hilde Van den Bulck \& Karen Donders (eds.). Public Service Media in the Networked Society. Ripe 2017. NORDICOM: University of Gothenburg.

Van der Haak, B. \& Parks M. \& Castells, M (2012). The future of Journalism: Networked Journalism. In International Journal of Communication 6: 2923-2938.

Van Dijck, J. (2013). The culture of connectivity: A critical history of social media. Oxford: Oxford University Press.

World Press Trends Database (2017). Consultado em 2 de Maio de 2018. Disponível em: http://www.wptdatabase.org/world-press-trends-2017-facts-and-figures 